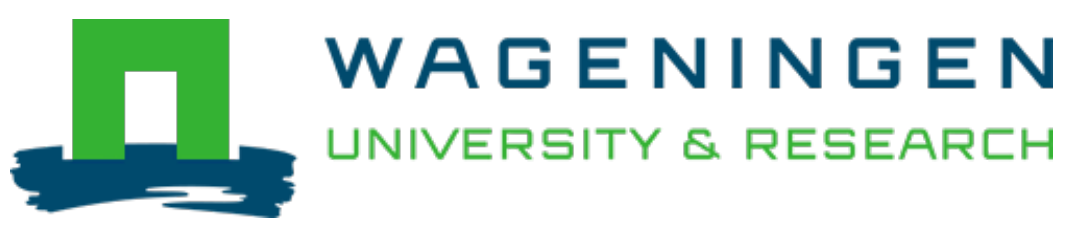

Overexpression of a putative nitrate transporter (StNPF1.11) increases plant
height, leaf chlorophyll content and tuber protein content of young potato plants Functional Plant Biology

Klaassen, Michiel T.; Dees, Dianka C.T.; Garrido, Rommel M.; Baéz, Jorge Alemán; Schrijen, Michiel et al https://doi.org/10.1071/FP19342

This article is made publicly available in the institutional repository of Wageningen University and Research, under the terms of article $25 \mathrm{fa}$ of the Dutch Copyright Act, also known as the Amendment Taverne. This has been done with explicit consent by the author.

Article 25 fa states that the author of a short scientific work funded either wholly or partially by Dutch public funds is entitled to make that work publicly available for no consideration following a reasonable period of time after the work was first published, provided that clear reference is made to the source of the first publication of the work.

This publication is distributed under The Association of Universities in the Netherlands (VSNU) 'Article $25 \mathrm{fa}$ implementation' project. In this project research outputs of researchers employed by Dutch Universities that comply with the legal requirements of Article $25 \mathrm{fa}$ of the Dutch Copyright Act are distributed online and free of cost or other barriers in institutional repositories. Research outputs are distributed six months after their first online publication in the original published version and with proper attribution to the source of the original publication.

You are permitted to download and use the publication for personal purposes. All rights remain with the author(s) and / or copyright owner(s) of this work. Any use of the publication or parts of it other than authorised under article $25 \mathrm{fa}$ of the Dutch Copyright act is prohibited. Wageningen University \& Research and the author(s) of this publication shall not be held responsible or liable for any damages resulting from your (re)use of this publication.

For questions regarding the public availability of this article please contact openscience.library@,wur.nl 


\title{
Overexpression of a putative nitrate transporter (StNPF1.11) increases plant height, leaf chlorophyll content and tuber protein content of young potato plants
}

\author{
Michiel T. Klaassen ${ }^{\mathrm{A}, \mathrm{B}}$, Dianka C. T. Dees ${ }^{\mathrm{A}}$, Rommel M. Garrido ${ }^{\mathrm{A}}$, Jorge Alemán Báez ${ }^{\mathrm{A}}$, \\ Michiel Schrijen ${ }^{\mathrm{A}}$, Pablo G. Baldeón Mendoza ${ }^{\mathrm{A}}$ and Luisa M. Trindade (D) A,C \\ AWageningen University and Research, Plant Breeding, PO Box 386, 6700 AJ Wageningen, The Netherlands. \\ ${ }^{B}$ Aeres University of Applied Sciences, Department of Applied Research, PO Box 374, 8250 AJ Dronten, \\ The Netherlands. \\ ${ }^{\mathrm{C} C o r r e s p o n d i n g}$ author. Email: luisa.trindade@wur.nl
}

\begin{abstract}
Nitrate $\left(\mathrm{NO}_{3}{ }^{-}\right)$fertilisers are commonly used to improve the yield and quality of most non-legume crops such as potato (Solanum tuberosum L.). Root cells absorb nitrate from the soil using plasma membrane-bound transporters. In this study, we overexpressed a putative nitrate transporter from potato (StNPF1.11) to study its effect on the level of tuber protein content in potato. At 10 weeks after planting, overexpression of StNPF1.11 increased the mean level of protein content of all $n=23$ transformants by $42 \%$ compared with the wild-type control. The level of chlorophyll content in leaves (from upper and lower plant parts) also increased for several individuals at 10 weeks. Tuber yield (fresh) was not structurally impaired; however, the mean tuber dry matter content of the transformants was reduced by $3-8 \%$ at 19 weeks. At 19 weeks, an overall increase in protein content was not clearly observed. Throughout plant development, half of the transformants were taller than the control. A basic understanding of the mechanisms that regulate plant nitrogen uptake, transport and utilisation, enable the development of tools to improve both crop nutrition and crop quality that are needed to enhance the viability and sustainability of future plant production systems.
\end{abstract}

Additional keywords: ion transport, plant nutrition, Solanum tuberosum, soluble protein.

Received 29 November 2019, accepted 16 December 2019, published online 25 March 2020

\section{Introduction}

Over the past two decades, much progress has been made in understanding molecular processes related to nitrate uptake and allocation in higher plants. Nitrate is taken up from the soil by proton-coupled plasma membrane-bound transporters of which numerous variants belong to the large nitrate transporter 1/peptide transporter family ( $N P F$, also known as the $N R T 1$ family), where co-transport of hydrogen ions $\left(\mathrm{H}^{+}\right)$provide the driving force of the system (Miller and Smith 1996; RuizCristin and Briskin 1991). Besides nitrate, studies in the plant model species Arabidopsis have illustrated that NPFs may also transport hormones and other molecules. These include the hormones auxin (Krouk et al. 2010) and abscisic acid (Kanno et al. 2012), dipeptides (Rentsch et al. 1998) and the amino acid histidine (Frommer et al. 1994). To capture nitrate under varying concentrations in the soil, plant root cells possess different NPFs that display low, high or dual affinities for nitrate acquisition (Krapp et al. 2014). Depending on the plant species, low-affinity NPFs (LATS) show linear kinetics $(K m)$ in the millimolar $(\mathrm{mM})$ range, whilst high-affinity NPFs (HATS) show a $K m$ of $\sim 5-100$ in $\mu \mathrm{M}$ concentrations (Doddema and Telkamp 1979; Goyal and Huffaker 1986;
Lee and Drew 1986; Aslam et al. 1992; Meharg and Blatt 1995). In general, LATS exhibit faster transporter systems than HATS (Touraine and Glass 1997). Dual-affinity transporters possess the ability to functions as both LATS and HATS (Liu et al. 1999). Plants regulate nitrate/nitrogen transport, assimilation and allocation according to nitrogen availability and need, by means of (post)-transcriptional and (post-)translational regulation (Meyer and Stitt 2001). After uptake from the soil, nitrate is added to the cell cytosolic pool or utilised directly. The use of nitrate by plants is orchestrated by the nitrogen satiety-status, where the availability of carbon and the cytosolic ion homeostasis are regulators. Nitrate may also be stored temporarily in vacuoles as a reserve (Martinoia et al. 1981). After uptake, nitrate is reduced to nitrite by nitrate reductase $(N R)$, subsequently nitrite is reduced to ammonium by nitrite reductase $(N i R)$. The glutamine synthetase $(G S)$ or glutamate synthase (GOGAT) and glutamate dehydrogenase $(G D H)$ pathways finally convert ammonium into the building blocks for the synthesis of amino acids, (storage) proteins, chlorophyll, nucleotides and other nitrogen-containing compounds that include (glyco) alkaloids, phenylpropanoids and glucosinolates. 
A plethora of molecular studies involving NPFs have been conducted in Arabidopsis, rice and wheat, as reviewed by Wang et al. (2018). Natural genetic variation of the rice OsNPF6.5/ $N R T 1.1 b$ gene has been hypothesised to have contributed to the diverged use of nitrate between rice subspecies (Hu et al. 2015). Overexpression of nitrate transporters has also been shown to induce large effects on key agronomic traits in different crops. For example, overexpression of the $\mathrm{pH}$-sensitive HATS OsNRT2.3b gene increased grain yield and improved the nitrogen-use efficiency (NUE) and phosphorous uptake and translocation in rice (Fan et al. 2016; Feng et al. 2017). NPFs may also play important roles in regulating key quality traits in other crops. However functional studies involving NPFS in important food crops, including potato (Solanum tuberosum L.), are still lacking. Here, we studied the overexpression effect of StNPF1.11 on the levels of protein content in tubers, leaf chlorophyll content, tuber yield and tuber dry matter content at 10 and 19 weeks after planting.

\section{Materials and methods}

StNPF1.11 underlies tuber protein content quantitative trait loci (QTL) identified in potato

The potato nitrate transporter gene (StNPF1.11; NCBI ID: XM_006355891) was selected from putative candidate genes underlying intervals spanning quantitative trait loci (QTL) for protein content in potato (Werij 2011; Klaassen et al. 2019a, $2019 b$ ). In potato, StNPF1.11 is located on chromosome 5 at the physical position of 7.436 Mb (PGSC Pseudomolecules v4.03). StNPF1.11 belongs to the large nitrate transporter 1/peptide transporter family (NPF) (http://plants.ensembl.org, accessed 15 January 2019). The DNA sequence of StNPF1.11 (PGSC0003DMG400015591) shows two gene models / splice variants (PGSC0003DMT400040275; PGSC0003DMT4000 40276) in the potato reference genome (PGSC Pseudomolecules v4.03). StNPF1.11 is orthologous to AtNPF1.1, AtNPF1.2 and AtNPF1.3 from Arabidopsis (see Fig. S7, available as Supplementary Material to this paper).

\section{Phylogenetic analysis}

Phylogenetic analysis was performed using MEGA ver. 7.0 (Kumar et al. 2016). Phylogenetic ties between the protein sequences from Arabidopsis and potato NPF genes were inferred using the neighbour-joining method (Saitou and Nei 1987). Distances were calculated using the Poisson correction method (Zuckerkandl and Pauling 1965). All sequences were collected from NCBI GenBank (https://www.ncbi.nlm.nih.gov/, accessed 18 October 2019).

\section{Cloning and construct design}

The construct (see Fig. S1 available as Supplementary Material to this paper) was designed for constitutive expression of StNPF1.11 by the CaMV 35S promoter from the cauliflower mosaic virus (Odell et al. 1985). The insert of StNPF1.11 was amplified from cDNA that originated from the tetraploid $(2 n=4 x=48)$ starch potato progenitor $K A 2005$ 1496 (Averis Seeds). Progenitor KA 2005-1496 was selected for cloning due to its high level of tuber protein content. PCR was performed using Phusion high-fidelity polymerase (NEB) according to the product protocol guideline. Gene specific PCR primers (see Table S1, available as Supplementary Material to this paper) were designed using Lasergene software (DNAStar). Isolation of the encoding fragment was carried out using the Qiagen Gel Purification Kit (Qiagen) according to the protocol of the manufacturer. Next, the encoding fragment was cloned using Gateway technology (Invitrogen) and sequenced for validation. The fragment was then transferred into pENTR donor vectors (Thermo Fisher Scientific) and later synthesised into Gateway pK7WG2 destination vectors (Invitrogen). Reactions were mediated by Gateway LR Clonase II enzyme mix (Invitrogen) as described by Karimi et al. (2002) to generate pK7WG2StNPF1.11 expression vectors. Isolated plasmids of the pK7WG2-StNPF1.11 expression vectors were transferred into competent A. tumerfaciens AGL1 cells via electroporation as described (Takken et al. 2000), and used for transformation.

\section{Transformation and regeneration}

The pK7WG2-StNPF1.11 expression vector (see Fig. S1, available as Supplementary Material to this paper) was introduced into the tetraploid $(2 n=4 x=48)$ starch potato variety Kardal (Averis Seeds). Kardal was selected for transformation due to its moderate and relatively stable level of tuber protein content. A. tumerfaciens-mediated transformation was performed as described (Heilersig et al. 2006). The developed StNPF1.11 transformants (OE-lines) were coded as OE- $x-y$, where $x$ denotes the generated series of the transformants and $y$ denotes the unique transformant line number. The wild-type control (untransformed Kardal) and T1 transformants were cultured from in vitro explants to develop biological replicates as described (Visser et al. 1991).

\section{Quantitative real-time PCR analysis}

The levels of gene expression were measured in different tissue types. Small leaves, large leaves, stems and small tubers were collected from the plants at 10 weeks after planting. At 19 weeks, large tubers were collected from the senesced plants. Small leaves were collected from the first to third compound leaf below the shoot apex. Larger compound leaves were collected from the sixth to ninth leaf below the shoot apex. Stem samples were collected from the internodes positioned at the centre of the plant. Collected tissues were frozen directly in liquid nitrogen and stored at $-80^{\circ} \mathrm{C}$. Isolation of RNA, cDNA synthesis and quantitative real-time PCR was conducted as described ( $\mathrm{Xu}$ et al. 2016). PCR primer sequences (see Table S2, available as Supplementary Material to this paper) were used to quantify the transcripts of StNPF1.11. Elongation factor-1 $\alpha(\mathrm{EF}-1 \alpha)$ was used as the reference gene (Nicot et al. 2005), as its expression is stable across different tissues in potato (Lopez-Pardo et al. 2013). The PCR efficiencies of the primer combinations were analysed using LinReqPCR software ver. 7.5 (Academic Medical Centre). The efficiencies of the PCR primer combinations ranged between the values 1.9-2.1 with a corresponding $R^{2}$ exceeding 0.95 . Relative gene expression was computed using the $2^{-\Delta \Delta \mathrm{CT}}$ method (Livak and Schmittgen 2001). 


\section{Greenhouse conditions}

The T1 transformants were planted in $3-\mathrm{L}$ pots as $10 \mathrm{~cm}$ sized in vitro plants. The plants were grown in a greenhouse (Unifarm). Biological replicates of transformants were grown in rows of eight consecutive plants. Complete rows of eight plants were randomly distributed in the greenhouse. The pots contained peat soil, fertilised with PG MIX 15-10-20 $(\mathrm{N}-\mathrm{P}-\mathrm{K})($ Yara Ltd) to $\mathrm{EC}=0.8$. Additionally, the plants were supplied with slow-release Osmocote Pro 19-9-10-2 (N-P-K$\mathrm{Mg}$ ) (Mertens) that also contained trace elements (TE) $\left(2 \mathrm{~g} \mathrm{~L}^{-1}\right)$. The growth trial was carried out from September 2017 to January 2018 ( $16 \mathrm{~h} \mathrm{light}$ at $20^{\circ} \mathrm{C} ; 8 \mathrm{~h}$ darkness at $18^{\circ} \mathrm{C}$ ). The in vitro plants from series 1 (OE-1; 16 transformants in total), were transferred to the greenhouse 1 week before those of series 2 (OE-2; 7 transformants in total).

\section{Leaf chlorophyll content}

Levels of leaf chlorophyll content (SPAD units) were measured in fully expanded compounds leaves, using the hand-held SPAD-502 device (Minolta Camera Co. Ltd). This device measured the transmittance of red $(650 \mathrm{~nm})$ and infrared $(940 \mathrm{~nm})$ radiation that passed through the leaves. Leaves from upper (fourth from apex) and lower (positioned $\sim 10 \mathrm{~cm}$ above the soil) plant parts were measured.

\section{Quantification of soluble tuber protein content}

Total soluble tuber protein content was quantified using SPRINT Rapid Protein Analyser (CEM Corp.) as described (Klaassen et al. 2019a). Purified potato tuber protein (AVEBE) was used to produce the calibration curve. Internal controls were included for diagnostic validation. Potato fruit juice (PFJ) was extracted from fresh tubers $(>1 \mathrm{~cm})$. Tuber fresh weight (yield) and tuber dry matter (DM) content were measured using a gravimetric scale. To determine total tuber DM, samples were dried to constant weight at $70^{\circ} \mathrm{C}$. Protein content $(\% \mathrm{w} / \mathrm{w})$ was expressed in milligram protein per gram tuber $\mathrm{FW}$. In our study, $1 \%$ protein represented $10 \mathrm{mg}$ of protein per $\mathrm{g}$ fresh tuber.

\section{Statistical analysis}

Data were analysed using Fisher's least significant difference (1.s.d.) post hoc test at $\alpha=0.05$ from one-way analysis of variance (ANOVA). Pearson's correlation coefficient $(r)$ was used to verify associations between the variables. Statistical analyses were conducted using SPSS ver. 23.0 (IBM Corp.). Principal components analyses were carried out using $\mathrm{R}$ software package Factoextra (https://cran.r-project.org/web/ packages/factoextra/index.html, accessed 9April 2019).

\section{Results}

\section{Variable StNPF1.11 expression between transformants}

We used quantitative real-time PCR to measure StNPF1.11 expression levels in the transformants. Expression of StNPF1.11 differed between the transformants (Fig. 1). The highest expression levels were observed in tissues from large leaves (up to 21-fold). Several transformants (e.g. OE-1-19) showed high expression levels of StNPF1.11 in multiple tissues, whilst others showed low values (e.g. OE-1-23 and OE-1-38).

\section{StNPF1.11 overexpression did not impair fresh tuber yield}

Tuber properties were measured to evaluate potential pleiotropic effects induced by StNPF1.11 overexpression. Tuber yield did not differ from the control (see Fig. S4, available as Supplementary Material to this paper). At 10 and 19 weeks, one and four of the 23 transformants showed reduced values for tuber yield (fresh weight) respectively. At 10 weeks, the tuber dry matter content of the transformants did not show clear differences compared with the control (see Fig. S5, available as Supplementary Material to this paper). However, at 19 weeks half of the transformants showed slightly reduced dry matter content (3-8\%) compared with the control.

\section{Stretched internodes and increased leaf chlorophyll content}

Half of the transformants were taller than the control (Fig. 2 and S2, available as Supplementary Material to this paper). The mean plant height of the two transformant series were

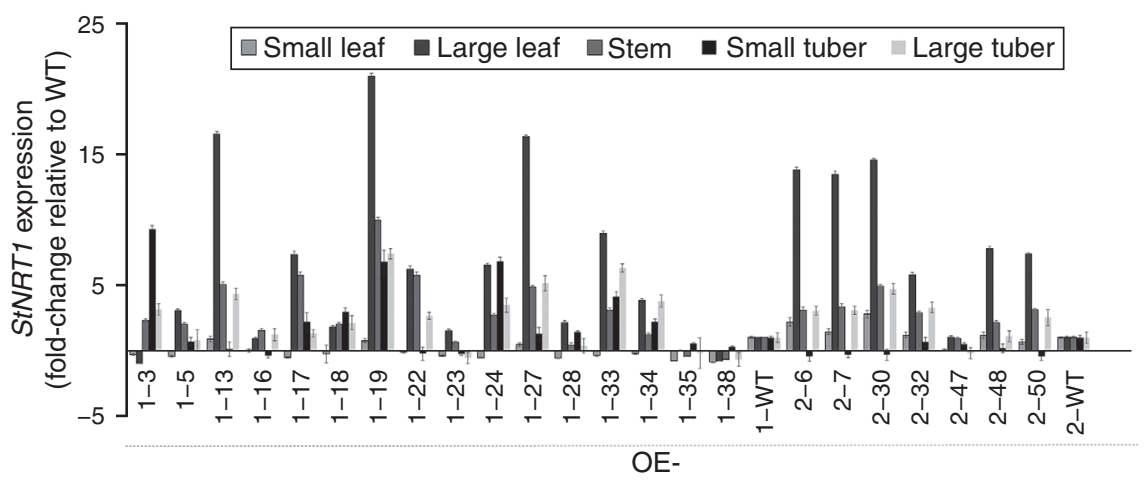

Fig. 1. Relative gene expression of StNPF1.11 (mean \pm s.d.) in small leaves, large leaves, stems, small tubers (all at 10 weeks) and large tubers (19 weeks). Quantitative real-time PCR were performed in $n=2$ technical replicates on pooled tissues that were collected from four biological replicates $(n=4)$. Abbreviations: OE, overexpression line; OE-1, series 1; OE-2, series 2; WT, wild-type control. 


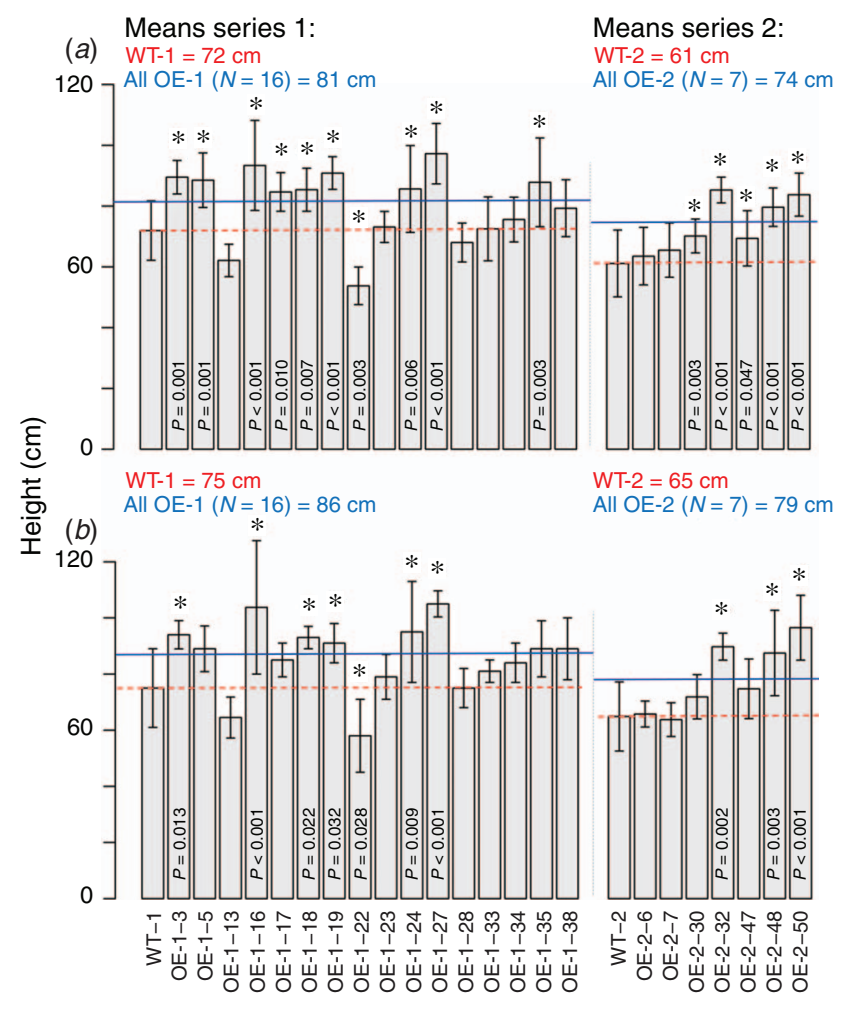

Fig. 2. Plant height (mean \pm s.d.) of the transformants at (a) 10 weeks and (b) 19 weeks. Data were collected from $n=6-8$ biological replicates at 10 weeks. At 19 weeks, four $(n=4)$ biological replicates were measured. The horizontal full lines and dashed lines represent the mean height for the transformants series and wild type control respectively. $P$ denotes Fisher's least significant difference (1.s.d.) probabilities from one-way ANOVA. Significant differences are indicated ${ }^{*}, \alpha=0.05$ relative to the wild-type (WT) control. Abbreviations: OE, overexpression line; OE-1, series 1 ; OE-2, series 2 .

increased (due to stretched internodes) by $13-21 \%$ and $15-22 \%$ at 10 and 19 weeks respectively. The height of one transformant (i.e. OE-1-22) was lower than the control. At 10 weeks, higher levels of chlorophyll content (SPAD units) were observed in leaves from lower and upper plant parts for several transformants. Transformant OE-2-50 showed the highest increase (39\%) compared with the control (Fig. 3). The mean level of chlorophyll content of the two transformant series were increased by $3-5 \%$ in lower leaves and $5-7 \%$ in upper leaves. At 19 weeks, chlorophyll content could not be measured as the leaves from the plants were senesced.

\section{Overexpression of StNPF1.11 increased tuber protein content in young tubers (10 weeks)}

At 10 weeks, the levels of tuber protein content were higher for all, but one, of the 23 transformants compared with the control (Fig. 4). At 10 weeks, the mean protein content of all transformants was $42 \%$ higher than the control. Several transformants (OE-1-19, OE-1-27, OE-2-30 and OE-2-50) showed strong increased values (73-126\%). At 19 weeks, overexpression of StNPF1.11 did not structurally increase protein content, although the two lines OE-1-19 and OE-1-

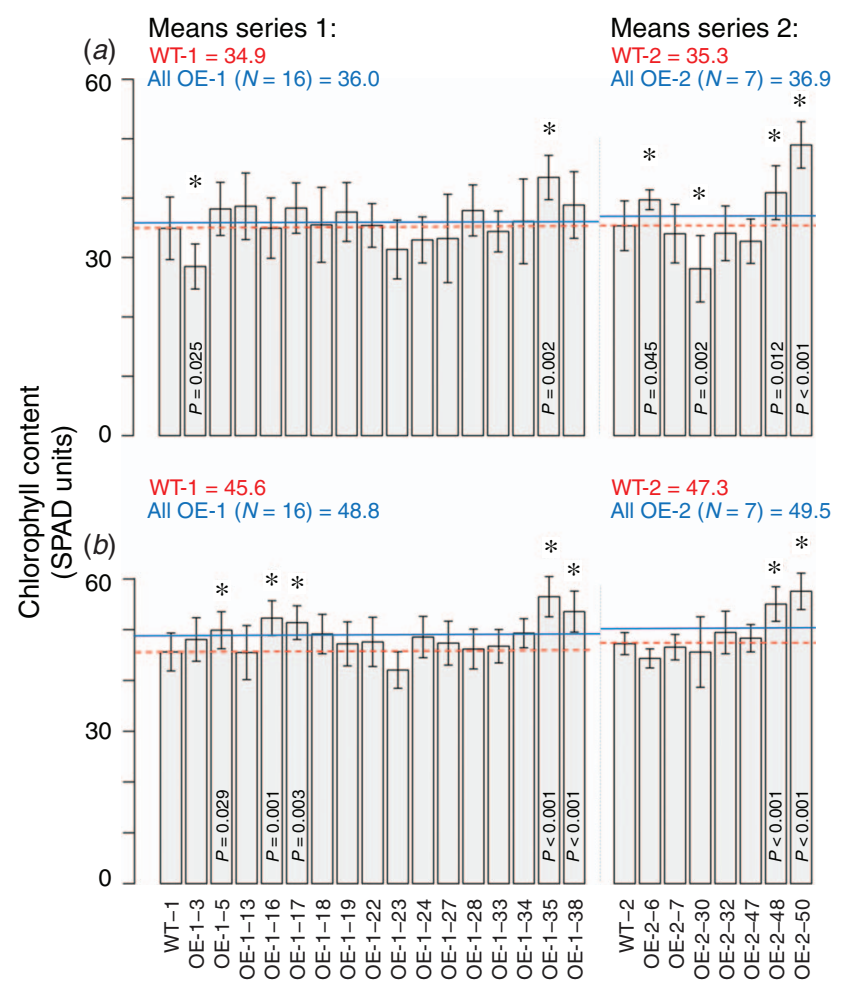

Fig. 3. Chlorophyll content in SPAD units (mean \pm s.d.) in (a) lower and (b) upper leaves of the transformants at 10 weeks. Data were collected from 6-8 biological replicates $(n=6-8)$, each measured in three technical replicates $(n=3)$. The horizontal full lines and dashed lines represent the average chlorophyll content for the transformants series and wild type control respectively. $P$ denotes Fisher's least significant difference (1.s.d.) probabilities from one-way ANOVA. Significant differences are indicated: *, $\alpha=0.05$ relative to the wild-type (WT) control. Abbreviations: OE, overexpression line; OE-1, series 1; OE-2, series 2.

27 still showed significantly higher values (28\%) and seven other transformants showed higher mean values but not significantly different. These transformants were also taller at 10 weeks compared with the control.

\section{Positive correlations between StNPF1.11 expression and tuber protein content}

Principal component and correlation analyses were carried out to evaluate the relationships between tissue-specific StNPF1.11 expression, plant properties and tuber traits (Fig. 5). The first two PCA components (dimensions) accounted for $51 \%$ of the variance, where the first and second components each explained 26 and $51 \%$ respectively. Moderate positive correlations $(r=0.36-0.50)$ were observed between tuber protein content versus StNPF1.11 expression in large leaves, stems and large tubers, especially at 10 weeks (see scatter bi-plots in Fig. S6, available as Supplementary Material to this paper). Moderate negative correlations were found between tuber dry matter content versus plant height ( $r=-0.31$ to -0.55$)$ and chlorophyll content in upper leaves ( $r=-0.34$ to -0.48 ; Fig. 5). At 10 weeks, protein content showed a moderate positive 


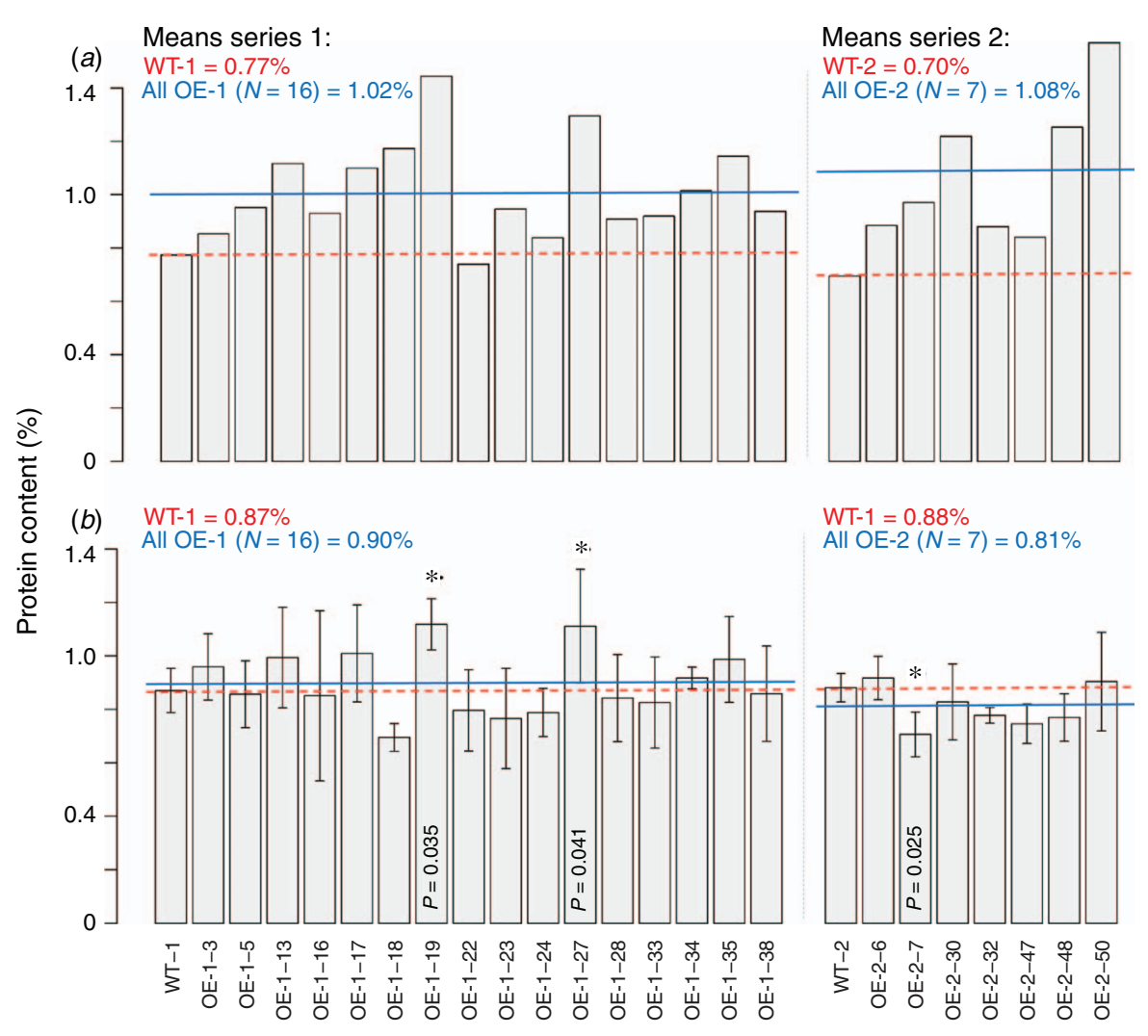

Fig. 4. Total soluble tuber protein content (mean \pm s.d.) of the transformants at (a) 10 weeks and (b) 19 weeks after planting. At 10 weeks, tubers from four biological replicates $(n=4)$ were pooled and measured, therefore no s.d. bars are shown. At 19 weeks, tubers were collected from four biological replicates $(n=4)$ that were measured individually. All samples were measured in two technical replicates $(n=2)$. The horizontal full lines and dashed lines represent the average protein content values for the transformants series and wild type controls respectively. $P$ represents Fisher's least significant difference (1.s.d.) probability value from one-way ANOVA. Significant differences are indicated: *, $\alpha=0.05$ relative to the wild-type (WT) control. Abbreviations: OE, overexpression line; OE-1, series 1 ; OE-2, series 2 .

correlation with chlorophyll content and plant height $(r=0.39$ to 0.48$)$, whereas at 19 weeks these correlations were weaker. Between 10 and 19 weeks, protein content, tuber yield (fresh) and tuber dry matter content again showed moderate positive correlations $(r=0.39-0.49)$ (Fig. 6). Plant height showed a high positive correlation between 10 and 19 weeks $(r=0.96)$.

\section{Discussion}

This study was carried out to investigate the overexpression effect of a putative nitrate transporter (StNPF1.11) on the level of tuber protein content in potato tubers. At 10 weeks, the levels of protein content were clearly higher for the transformants compared with the wild-type control, whereas at 19 weeks a clear overall increase was not observed for all transformants. Taller plants were observed during both stages of plant development, and several transformants showed increased leaf chlorophyll content at 10 weeks. Moderate positive correlations were found between protein content and StNPF1.11 expression levels in leaves, tubers and stems. Our results showed that overexpression of StNPF1.11 affected tuber protein content, leaf chlorophyll content and plant height.

\section{Overexpression of StNPF1.11 increased leaf chlorophyll and tuber protein content at 10 weeks}

The levels of chlorophyll (a molecule containing four nitrogen atoms) content were higher in the leaves of several transformants (Fig. 3). In literature it has been shown that leaf chlorophyll content (deduced from SPAD values) shows a high positive correlation with total leaf nitrogen $(\mathrm{N})$ content (Gianquinto et al. 2004). Nitrogen has been suggested to affect leaf thickness (Peng 1992). Therefore, it is noteworthy to investigate whether leaf thickness, cell size or the density of chloroplasts caused the increased levels of leaf chlorophyll content.

At 10 weeks, overexpression of StNPF1.11 structurally increased the level of tuber protein content by up to $126 \%$ (Fig. 4). At this stage of plant development, the mean level of protein content for all transformants was $42 \%$ higher than the 


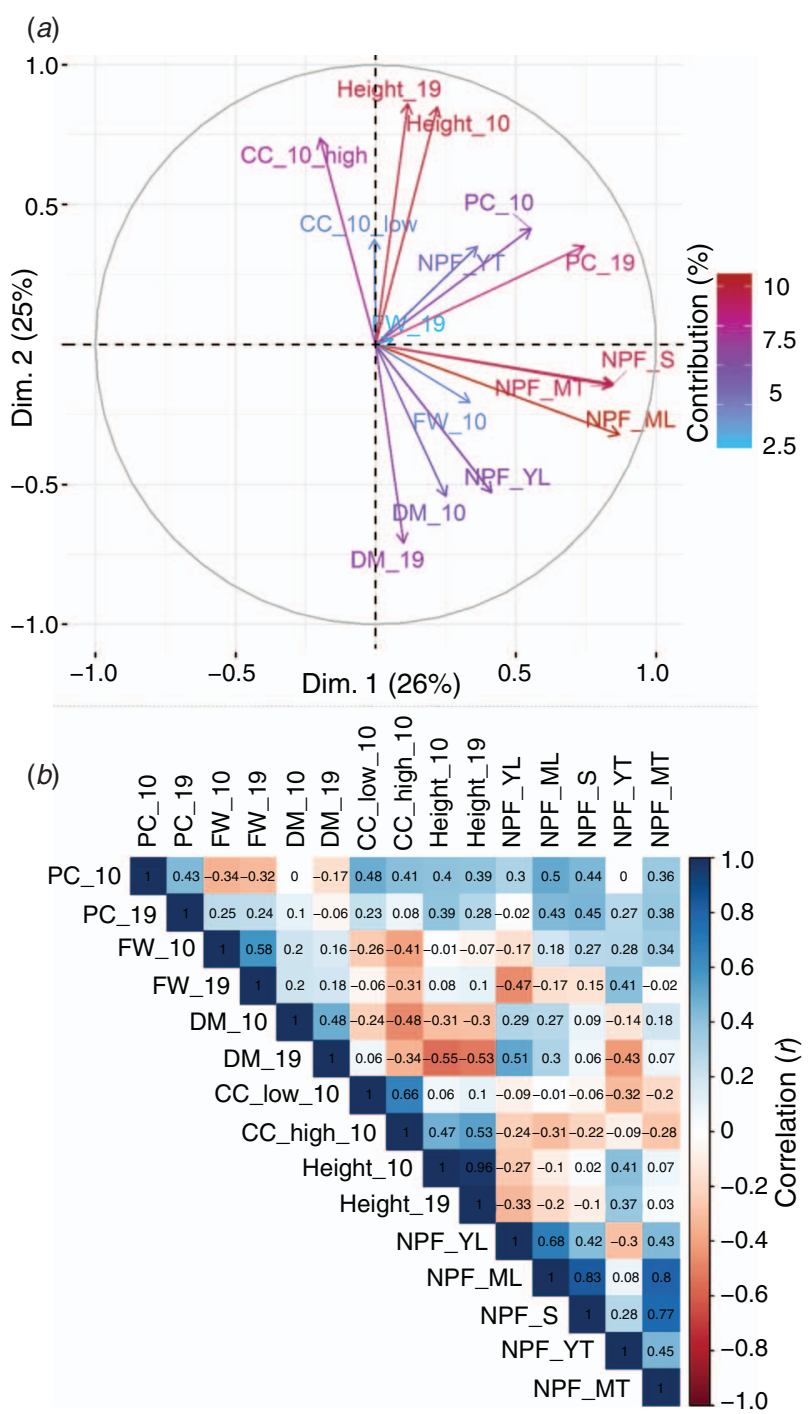

Fig. 5. (a) Principal components bi-plot and (b) correlation matrix for tissue-specific expression of StNPF1.11, tuber protein content, tuber yield, tuber dry matter content, leaf chlorophyll content and plant height of the transformants. Length of the arrows approximate the variance explained by the variables. The numbers in matrix show the correlation coefficient (Pearson's $r$ ) between the variables. Abbreviations: PC, tuber protein content; FW, tuber yield; DM, tuber dry matter content; CC, leaf chlorophyll content; NPF, StNPF1.11 expression; YL, small leaf; ML, large leaf; S, stem; YT, small tuber; MT, large tuber; 10, 10 weeks; 19, 19 weeks; Dim, dimension.

control. This structural effect was not clearly observed at 19 weeks. At this developmental stage merely two of the twenty three transformants showed significantly increased values (28\%), although several other transformants showed higher non-significant values. Different substrates have been reported to be transported by plant $N P F$ proteins, as shown in Arabidopsis (Chiba et al. 2015). Our data suggest that StNPF1.11 may be involved in $\mathrm{N}$ transport in young potato plants, as both the levels of tuber protein content and leaf chlorophyll content (that is associated with total leaf nitrogen) were higher than the control at 10 weeks. It remains unclear to us why we observed clear differences for protein content at 10 weeks but not at 19 weeks. Whether transcriptional or translational factors played a role remains to be elucidated. The levels of protein content showed variation between the transformants (Fig. 4). This variation may have been caused by spatial (Fig. 1) and temporal differences in StNPF1.11 expression. Transcripts from CaMV $35 \mathrm{~S}$ promoter-driven constructs may differ both spatially and temporally, as shown in tobacco (Williamson et al. 1989). Williamson et al. (1989) demonstrated that CaMV 35S directed expression was higher in young active tissues than in older quiescent types. Also, transcription enhancers positioned upstream of the CaMV 35S promoter (Fang et al. 1989) may also lead to differential accumulation of transcripts in different tissues. The number of construct inserts and the chromosome environments may also have played a role. To explore interactions between N-responsive genes in the nitrogen assimilation pathway and putative nitrate transporters (NPF genes), amino acid transporters and peptide transporters in potato, it is certainly relevant to study the overexpression effects of StNPF1.11 as well as other $N P F$ transporters from this gene family (see Fig. S7, available as Supplementary Material to this paper). The use of tissue-specific promoters, e.g. from the potato tuber granulebound starch synthase (GBSS) gene or patatin genes, may elicit more specific responses in harvestable (i.e. matured) potatoes. The use of different genetic backgrounds and contrasting soil $\mathrm{N}$-conditions, present promising designs to study the (dynamic) biological functions of $N P F$ genes in more detail. Also, dedicated molecular studies will reveal which specific substrates are transported by StNPF1.11

Overexpression of StNPF1.11 did not impair tuber yield but mildly reduced tuber dry matter content

Overexpression of StNPF1.11 did not impair tuber yield of the transformants at 10 and 19 weeks compared with the control. Plant height of the transformants was increased by overexpressing StNPF1.11, both at 10 and 19 weeks. As an indirect effect, the mean tuber dry matter content of the transformants was reduced by 3-8\% (see Fig. S5, available as Supplementary Material to this paper). Very high Nfertiliser rates tend to stimulate vegetative growth in potato plants, which coincides with reduced tuber yield and reduced tuber dry matter content and increased $\mathrm{N}$ content in tubers (Westermann et al. 1994; Bélanger et al. 2002; Zebarth and Rosen 2007). Nitrogen is also known to delay the onset of flowering and senescence in plants (Castro Marín et al. 2011). Delayed flowering subsequently prolongs the period of maturation and may affect the bulking-dynamics of storage compounds (e.g. starch) (Withrow 1945; Scott et al. 1973). Overexpression of StNPF1.11 may therefore have stimulated vegetative plant growth due to increased uptake of $\mathrm{N}$, resulting in taller plants (see Fig. S2, available as Supplementary Material to this paper). Increased vegetative growth may subsequently have altered the tuber sink strength, potentially leading to reduced tuber dry matter content for half (but not all) of the transformants at 19 weeks. Hence, 

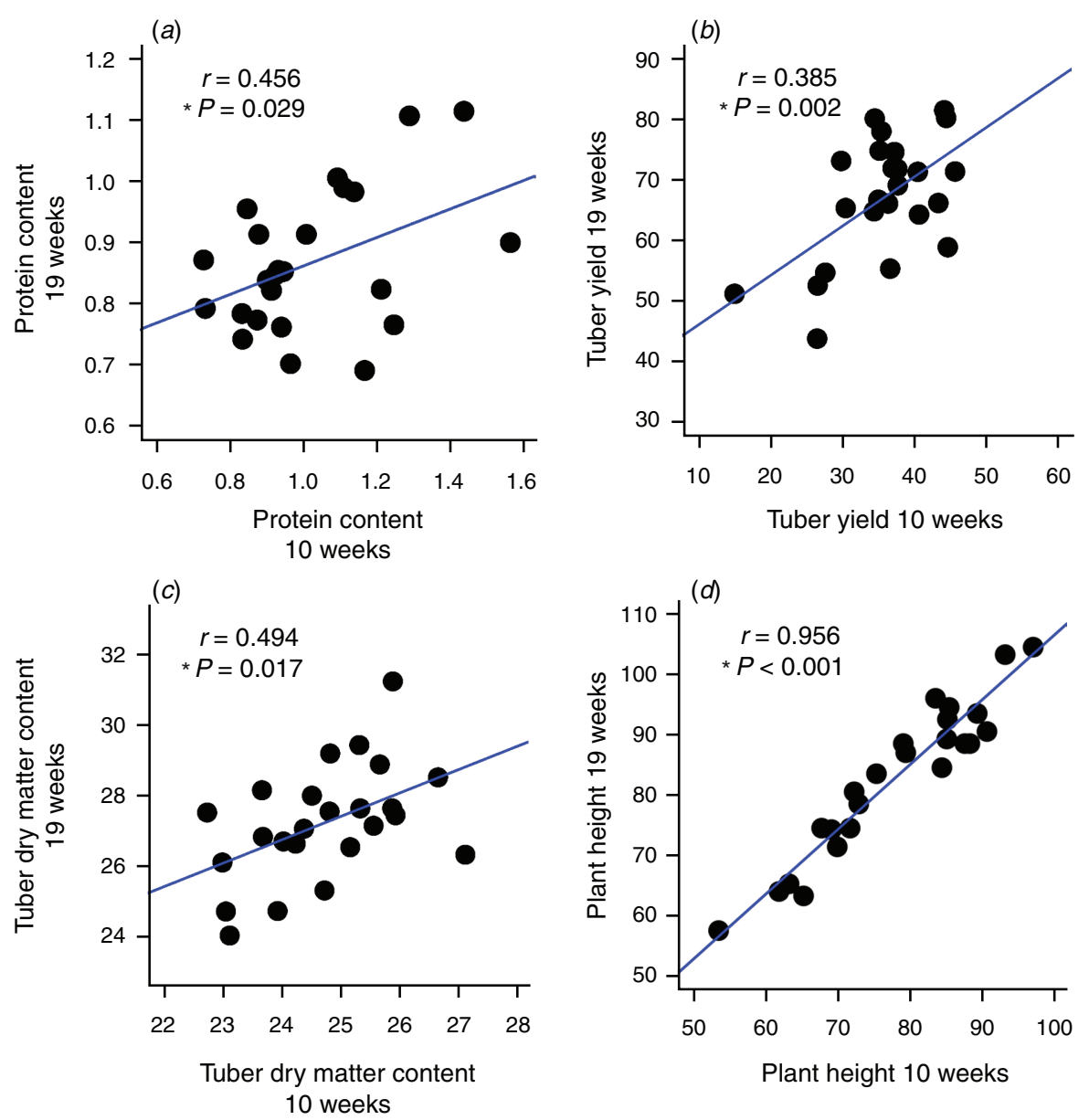

Fig. 6. Scatter plots for $(a)$ tuber protein content, $(b)$ tuber yield, $(c)$ tuber dry matter content and (d) plant height of the transformants at 10 vs 19 weeks. Linear regression lines are shown: $r$ represents Pearson's correlation coefficients; $P$ represents probability values; significant relationships are indicated: *, $\alpha=0.05$.

dissecting the potential effect of StNPF1.11 on sink strength is certainly worthwhile. Moreover, it is relevant to study the interplay between the major maturity regulator in potato $(S t C D F 1)$ and NPF transporters as their transcription patterns seem to be linked (Varala et al. 2018). These studies may also provide insight into tuber sink strength and the $\mathrm{C} / \mathrm{N}$ balance.

\section{Molecular functions of the StNPF1.11 gene}

The protein sequence of StNPF1.11 is orthologous to three Arabidopsis NPF genes (see Fig. S7, available as Supplementary Material to this paper: AtNPF1.1, AtNPF1.2 and AtNPF1.3). AtNPF1.1 and AtNPF1.2 are capable of translocating nitrate, gibberellin (GA) and jasmonoylisoleucine (JA-Ile) (Hsu and Tsay 2013; Chiba et al. 2015). AtNPF1.1 is also able to transport abscisic acid (ABA) (Chiba et al. 2015). At present it is still unknown which substrates are transported by AtNPF1.3. We observed stretched internodes that may have resulted from altered GA transport. GA is a well-known plant hormone that modulates shoot elongation by stimulating cell division and elongation (Kende and Zeevaart 1997; Hedden and Proebsting 1999). We showed that tuber protein content and leaf chlorophyll content were higher at 10 weeks. Increased nitrogen or nitrate uptake by overexpressing StNPF1.11 may have caused these effects, but this must still be demonstrated empirically. Without doubt, future studies will be conducted to verify whether GA, nitrate or potentially other compounds are transported by StNPF1.11. It has been proposed that NPF proteins function as single components for low-affinity nitrate transport (Liu and Tsay 2003). Overexpressing of StNPF1.11 induced clear phenotypic effects, therefore we hypothesise that StNPF1.11 is able to function as a single component that apparently does not require a partner protein. It has been reported that several high-affinity (HATS) nitrate transporters require a partner protein to function (Zhou et al. 2000), whereas this has not been shown for low-affinity nitrate (LATS) transporters. In any case, molecular studies are needed to validate the putative LATS property of StNPF1.11 and its substrate binding affinity. 


\section{Concluding remarks}

Taken together, this study clearly demonstrated that overexpression of a putative nitrate transporter (StNPF1.11) from potato structurally increased tuber protein content and leaf chlorophyll content of young potato plants. Moreover, stretched internodes were observed throughout plant development. For the first time, we report that tuber protein content was increased by overexpressing a potato (NPF transporter) gene.

\section{Conflicts of interest}

The authors declare no conflicts of interest.

\section{Acknowledgements}

Michiel T. Klaassen was funded by Aeres University of Applied Sciences, the Centre for Biobased Economy (CBBE), AVEBE and Averis Seeds B. $\mathrm{V}$. These funds are gratefully acknowledged. The authors kindly thank Dirk Jan Huigen and Henk Meurs for practical assistance to carry out the growth trials.

\section{References}

Aslam M, Travis RL, Huffaker RC (1992) Comparative kinetics and reciprocal inhibition of nitrate and nitrite uptake in roots of uninduced and induced barley (Hordeum vulgare L.) seedlings. Plant Physiology 99(3), 1124-1133. doi:10.1104/pp.99.3.1124

Bélanger G, Walsh JR, Richards JE, Milburn PH, Ziadi N (2002) Nitrogen fertilization and irrigation affects tuber characteristics of two potato cultivars. American Journal of Potato Research 79(4), 269-279. doi:10.1007/BF02986360

Castro Marín IC, Loef I, Bartetzko L, Searle I, Coupland G, Stitt M, Osuna D (2011) Nitrate regulates floral induction in Arabidopsis, acting independently of light, gibberellin and autonomous pathways. Planta 233(3), 539-552. doi:10.1007/s00425-010-1316-5

Chiba Y, Shimizu T, Miyakawa S, Kanno Y, Koshiba T, Kamiya Y, Seo M (2015) Identification Arabidopsis thaliana NRT1/PTR FAMILY (NPF) proteins capable of transporting plant hormones. Journal of Plant Research 128(4), 679-686. doi:10.1007/s10265-015-0710-2

Doddema H, Telkamp G (1979) Uptake of nitrate by mutants of Arabidopsis thaliana, disturbed in uptake or reduction of nitrate: II. Kinetics. Physiologia Plantarum 45(3), 332-338. doi:10.1111/ j.1399-3054.1979.tb02593.x

Fan X, Tang Z, Tan Y, Zhang Y, Luo B, Yang M, Lian X, Shen Q, Miller AJ, $\mathrm{Xu} \mathrm{G}$ (2016) Overexpression of a $\mathrm{pH}$-sensitive nitrate transporter in rice increases crop yields. Proceedings of the National Academy of Sciences of the United States of America 113(26), 7118-7123. doi:10.1073/ pnas. 1525184113

Fang R-X, Nagy F, Sivasubramaniam S, Chua N-H (1989) Multiple cis regulatory elements for maximal expression of the cauliflower mosaic virus $35 \mathrm{~S}$ promoter in transgenic plants. The Plant Cell 1(1), 141-150.

Feng H, Li B, Zhi Y, Chen J, Li R, Xia X, Xu G, Fan X (2017) Overexpression of the nitrate transporter, OsNRT2.3b, improves rice phosphorus uptake and translocation. Plant Cell Reports 36(8), 1287-1296. doi:10.1007/s00299-017-2153-9

Frommer WB, Hummel S, Rentsch D (1994) Cloning of an Arabidopsis histidine transporting protein related to nitrate and peptide transporters. FEBS Letters 347(2-3), 185-189. doi:10.1016/00145793(94)00533-8

Gianquinto G, Goffart JP, Olivier M, Guarda G, Colauzzi M, Dalla Costa L, Delle Vedove G, Vos J, Mackerron DKL (2004) The use of hand-held chlorophyll meters as a tool to assess the nitrogen status and to guide nitrogen fertilization of potato crop. Potato Research 47, 35-80. doi:10.1007/BF02731970
Goyal S, Huffaker R (1986) A novel approach and a fully automated microcomputer-based system to study kinetics of $\mathrm{NO}_{3}{ }^{-}, \mathrm{NO}_{2}{ }^{-}$, and $\mathrm{NH}_{4}{ }^{+}$transport simultaneously by intact wheat seedlings. Plant, Cell \& Environment 9(3), 209-215. doi:10.1111/j.1365-3040.1986. tb01734.x

Hedden P, Proebsting WM (1999) Genetic analysis of gibberellin biosynthesis. Plant Physiology 119(2), 365-370. doi:10.1104/pp.119. 2.365

Heilersig BH, Loonen AE, Wolters A-MA, Visser RG (2006) Presence of an intron in inverted repeat constructs does not necessarily have an effect on efficiency of post-transcriptional gene silencing. Molecular Breeding 17 (4), 307-316. doi:10.1007/s11032-006-9001-x

Hsu P-K, Tsay Y-F (2013) Two phloem nitrate transporters, NRT1. 11 and NRT1. 12, are important for redistributing xylem-borne nitrate to enhance plant growth. Plant Physiology 163(2), 844-856. doi:10.1104/ pp.113.226563

Hu B, Wang W, Ou S, Tang J, Li H, Che R, Zhang Z, Chai X, Wang H, Wang Y (2015) Variation in NRT1. 1B contributes to nitrate-use divergence between rice subspecies. Nature Genetics 47(7), 834. doi:10.1038/ ng. 3337

Kanno Y, Hanada A, Chiba Y, Ichikawa T, Nakazawa M, Matsui M, Koshiba T, Kamiya Y, Seo M (2012) Identification of an abscisic acid transporter by functional screening using the receptor complex as a sensor. Proceedings of the National Academy of Sciences of the United States of America 109(24), 9653-9658. doi:10.1073/pnas.1203567109

Karimi M, Inzé D, Depicker A (2002) GATEWAY ${ }^{\mathrm{TM}}$ vectors for Agrobacterium-mediated plant transformation. Trends in Plant Science 7(5), 193-195. doi:10.1016/S1360-1385(02)02251-3

Kende H, Zeevaart J (1997) The five 'classical' plant hormones. The Plant Cell 9(7), 1197. doi:10.1105/tpc.9.7.1197

Klaassen MT, Bourke PM, Maliepaard C, Trindade LM (2019a) Multiallelic QTL analysis of protein content in a bi-parental population of cultivated tetraploid potato. Euphytica 215(2), 14. doi:10.1007/ s10681-018-2331-z

Klaassen MT, Willemsen JH, Vos PG, Visser RG, van Eck HJ, Maliepaard CA, Trindade LM (2019b) Genome-wide association analysis in tetraploid potato reveals four QTLs for protein content. Molecular Breeding 39, 151. doi:10.1007/s11032-019-1070-8

Krapp A, David LC, Chardin C, Girin T, Marmagne A, Leprince A-S, Chaillou S, Ferrario-Méry S, Meyer C, Daniel-Vedele F (2014) Nitrate transport and signalling in Arabidopsis. Journal of Experimental Botany 65(3), 789-798. doi:10.1093/jxb/eru001

Krouk G, Lacombe B, Bielach A, Perrine-Walker F, Malinska K, Mounier E, Hoyerova K, Tillard P, Leon S, Ljung K (2010) Nitrate-regulated auxin transport by NRT1. 1 defines a mechanism for nutrient sensing in plants. Developmental Cell 18(6), 927-937. doi:10.1016/ j.devcel.2010.05.008

Kumar S, Stecher G, Tamura K (2016) MEGA7: molecular evolutionary genetics analysis version 7.0 for bigger datasets. Molecular Biology and Evolution 33(7), 1870-1874. doi:10.1093/molbev/msw054

Lee R, Drew M (1986) Nitrogen-13 studies of nitrate fluxes in barley roots: II. Effect of plant N-status on the kinetic parameters of nitrate influx. Journal of Experimental Botany 37(12), 1768-1779. doi: $10.1093 / \mathrm{jxb} / 37.12 .1768$

Liu KH, Tsay YF (2003) Switching between the two action modes of the dual-affinity nitrate transporter CHL1 by phosphorylation. EMBO Journal 22(5), 1005-1013. doi:10.1093/emboj/cdg118

Liu K-H, Huang C-Y, Tsay Y-F (1999) CHL1 is a dual-affinity nitrate transporter of Arabidopsis involved in multiple phases of nitrate uptake. The Plant Cell 11(5), 865-874. doi:10.1105/tpc.11.5.865

Livak KJ, Schmittgen TD (2001) Analysis of relative gene expression data using real-time quantitative PCR and the $2^{-\Delta \Delta \mathrm{CT}}$ method. Methods 25(4), 402-408. doi:10.1006/meth.2001.1262

Lopez-Pardo R, Ruiz de Galarreta JI, Ritter E (2013) Selection of housekeeping genes for qRT-PCR analysis in potato tubers under cold 
stress. Molecular Breeding 31(1), 39-45. doi:10.1007/s11032-0129766-z

Martinoia E, Heck U, Wiemken A (1981) Vacuoles as storage compartments for nitrate in barley leaves. Nature 289(5795), 292. doi:10.1038/ $289292 \mathrm{a} 0$

Meharg A, Blatt M (1995) $\mathrm{NO}_{3}{ }^{-}$transport across the plasma membrane of Arabidopsis thaliana root hairs: kinetic control by $\mathrm{pH}$ and membrane voltage. The Journal of Membrane Biology 145(1), 49-66. doi:10.1007/ BF00233306

Meyer C, Stitt M (2001) Nitrate reduction and signalling. In 'Plant nitrogen'. (Eds PJ Lea, JF Morot-Gaudry) pp. 37-59. (Springer: Berlin)

Miller AJ, Smith SJ (1996) Nitrate transport and compartmentation in cereal root cells. Journal of Experimental Botany 47(7), 843-854. doi: $10.1093 / \mathrm{jxb} / 47.7 .843$

Nicot N, Hausman J-F, Hoffmann L, Evers D (2005) Housekeeping gene selection for real-time RT-PCR normalization in potato during biotic and abiotic stress. Journal of Experimental Botany 56(421), 2907-2914. doi:10.1093/jxb/eri285

Odell JT, Nagy F, Chua N-H (1985) Identification of DNA sequences required for activity of the cauliflower mosaic virus $35 \mathrm{~S}$ promoter. Nature 313, 810. doi:10.1038/313810a0

Peng S (1992) Leaf thickness affects the estimation of leaf nitrogen concentration using a chlorophyll meter. International Rice Research Notes 17, 19-20.

Rentsch D, Boorer K, Frommer W (1998) Structure and function of plasma membrane amino acid, oligopeptide and sucrose transporters from higher plants. The Journal of Membrane Biology 162(3), 177-190. doi:10.1007/s002329900355

Ruiz-Cristin J, Briskin DP (1991) Characterization of a $\mathrm{H}^{+} \mathrm{NO}_{3}{ }^{-}$symport associated with plasma membrane vesicles of maize roots using ${ }^{36} \mathrm{CIO}_{3}{ }^{-}$as a radiotracer analog. Archives of Biochemistry and Biophysics 285(1), 74-82. doi:10.1016/0003-9861(91)90330-L

Saitou N, Nei M (1987) The neighbor-joining method: a new method for reconstructing phylogenetic trees. Molecular Biology and Evolution 4 (4), 406-425.

Scott R, Ogunremi E, Ivins J, Mendham N (1973) The effect of fertilizers and harvest date on growth and yield of oilseed rape sown in autumn and spring. The Journal of Agricultural Science 81(2), 287-293. doi:10.1017/S0021859600058949

Takken FL, Luderer R, Gabriëls SH, Westerink N, Lu R, De Wit PJ, Joosten MH (2000) A functional cloning strategy, based on a binary PVXexpression vector, to isolate HR-inducing cDNAs of plant pathogens. The Plant Journal 24(2), 275-283. doi:10.1046/j.1365-313x. 2000.00866.x

Touraine B, Glass $\mathrm{AD}$ (1997) $\mathrm{NO}_{3}{ }^{-}$and $\mathrm{ClO}_{3}{ }^{-}$fluxes in the chl1-5 mutant of Arabidopsis thaliana (Does the CHL1-5 gene encode a low-affinity
$\mathrm{NO}_{3}{ }^{-}$transporter?). Plant Physiology 114(1), 137-144. doi:10.1104/ pp.114.1.137

Varala K, Marshall-Colón A, Cirrone J, Brooks MD, Pasquino AV, Léran S, Mittal S, Rock TM, Edwards MB, Kim GJ (2018) Temporal transcriptional logic of dynamic regulatory networks underlying nitrogen signaling and use in plants. Proceedings of the National Academy of Sciences of the United States of America 115(25), 6494-6499. doi:10.1073/pnas.1721487115

Visser RG, Stolte A, Jacobsen E (1991) Expression of a chimaeric granulebound starch synthase-GUS gene in transgenic potato plants. Plant Molecular Biology 17(4), 691-699. doi:10.1007/BF00037054

Wang YY, Cheng YH, Chen KE, Tsay YF (2018) Nitrate transport, signaling, and use efficiency. Annual Review of Plant Biology 69, 85-122. doi:10.1146/annurev-arplant-042817-040056

Werij JS (2011) Genetic analysis of potato tuber quality traits. PhD thesis, Wageningen University, Wageningen, The Netherlands. Available at http://edepot.wur.nl/183746 [Verified 19 February 2020]

Westermann D, Tindall T, James D, Hurst R (1994) Nitrogen and potassium fertilization of potatoes: yield and specific gravity. American Potato Journal 71(7), 417-431. doi:10.1007/BF02849097

Williamson JD, Hirsch-Wyncott ME, Larkins BA, Gelvin SB (1989) Differential accumulation of a transcript driven by the CaMV 35S promoter in transgenic tobacco. Plant Physiology 90(4), 1570-1576. doi:10.1104/pp.90.4.1570

Withrow AP (1945) The interrelationship of nitrogen supply and photoperiod on the flowering, growth and stem anatomy of certain long and short day plants. Butler University Botanical Studies 7, $40-64$.

Xu X, Dechesne A, Visser RG, Trindade LM (2016) Expression of an (engineered) 4,6- $\alpha$-glucanotransferase in potato results in changes in starch characteristics. PLoS One 11(12), e0166981. doi:10.1371/journal. pone.0166981

Zebarth B, Rosen CJ (2007) Research perspective on nitrogen BMP development for potato. American Journal of Potato Research 84(1), 3-18. doi:10.1007/BF02986294

Zhou J-J, Fernández E, Galván A, Miller AJ (2000) A high affinity nitrate transport system from Chlamydomonas requires two gene products. FEBS Letters 466(2-3), 225-227. doi:10.1016/S0014-5793(00)01085-1

Zuckerkandl E, Pauling L (1965) Evolutionary divergence and convergence in proteins. In 'Evolving genes and proteins'. (Eds V Bryson, HJ Vogel) pp. 97-166. (Academic Press: New York)

Handling Editor: Ulrike Mathesius 